\title{
IMPACTOS DAS OBRAS COSTEIRAS NA MORFOLOGIA DA LINHA DE COSTA: O CASO DO PORTO DO AÇU, SÃO JOÃO DA BARRA, RJ
}

\author{
Luca Lämmle $^{(a)}$, Eduardo Manuel Rosa Bulhoes ${ }^{(b)}$ \\ (a) Programa de Pós-Graduação em Geografia, Universidade Federal Fluminense, lucal@id.uff.br \\ (b) Programa de Pós-Graduação em Geografia, Universidade Federal Fluminense, eduardobulhoes@id.uff.br
}

\section{Eixo: DINÂMICA E GESTÃO DE ZONAS COSTEIRAS}

\begin{abstract}
Resumo
Com construção iniciada em outubro de 2007 e área total de 90 km², o Porto do Açu é um complexo portuário privativo de uso misto e se trata de um projeto inovador da empresa Prumo - logística global, com dois terminais, um offshore (costa afora) e outro onshore (costa adentro), em construção no município de São João da Barra, localizado no litoral Norte Fluminense, próximo à Bacia de Campos, área responsável por $85 \%$ da produção de petróleo e gás do Brasil. O objetivo deste trabalho é identificar as alterações ocorridas na morfologia da linha de costa do litoral, que abrange a área de influência direta do Porto do Açu a partir da construção das obras costeiras relacionadas ao porto e pretende demonstrar a dinâmica da linha de costa antes e após a instalação das obras portuárias. As crescentes intervenções que vem sendo feitas na área de estudo é a principal justificativa para a realização deste estudo. Os resultados mostraram que houve uma progradação na linha de costa de 7,792 hectares e retrogradação de 1,325 hectares. Tais resultados estão baseados na posição da linha de costa em seis diferentes anos, partindo do que está disponível no Google Earth Pro e posteriormente a utilização de softwares de geoprocessamento para obter estes números.
\end{abstract}

Palavras chave: Porto do Açu; Obras Portuárias; Linha de Costa; Progradação; Retrogradação.

\section{Introdução}

As zonas costeiras são consideradas ambientes extremamente frágeis e importantes para o meio ambiente, por se tratarem de ecossistemas limítrofes, de transição, e comportam diferentes tipos de clima, como é o caso do litoral brasileiro, que varia do úmido equatorial e tropical ao semiárido no Nordeste, além do subtropical no Sul (NORDSTROM, 2010). São importantes também pela diversidade de ecossistemas existentes nestes ambientes, que além das praias arenosas, destacam-se estuários e lagoas costeiras, sistemas lagunares margeados por manguezais, praias lodosas, costões rochosos, recifes de coral, plataformas arenosas, bancos de algas calcárias, restingas, ilhas costeiras e oceânicas, etc. Portanto, as áreas costeiras se alteram a todo o momento, intensificando ainda mais esse processo quando há interferência humana impondo algum obstáculo na dinâmica natural do oceano.

No Brasil, em função da maior ocupação nas áreas litorâneas ao longo da história e o desenvolvimento de técnicas e conhecimentos sobre o oceano em resposta ao crescimento econômico, os portos e consequentemente as obras portuárias, que tem como finalidade a criação de uma área protegida para as 
operações frente à agitação oceânica (exceto os portos em mar aberto, que podem ser na forma de píeres ou Jetties, por exemplo), vem se tornando cada vez mais comuns.

O Porto do Açu é um complexo portuário privativo de uso misto e se trata de um projeto inovador da empresa Prumo - logística global, com dois terminais, um offshore (costa afora) e outro onshore (costa adentro), em construção em São João da Barra (RJ), próximo à Bacia de Campos, área responsável por $85 \%$ da produção de petróleo e gás do Brasil. De acordo com o projeto inicial, ele terá $17 \mathrm{~km}$ de píeres e poderá receber até 47 embarcações, segundo a Prumo logística. O empreendimento estará preparado para receber navios de grande porte, como Capesize e Very Large Crude Carrier (VLCCs), que transportam até 320 mil toneladas de carga. Segundo a empresa responsável pelo porto, atualmente, somente $7 \%$ dos portos brasileiros possuem capacidade para receber navios capesize.

Com construção iniciada em outubro de 2007 e área total de $90 \mathrm{~km}^{2}$, o canal de acesso ao Porto do Açu terá profundidade de até 25 metros e se localiza a $15 \mathrm{~km}$ ao norte do Cabo de São Tomé / $30 \mathrm{~km}$ ao sul do Rio Paraíba do Sul.

$\mathrm{Na}$ análise do RIMA, produzido para fins de licenciamento ambiental, foi verificado que está previsto que um processo erosivo decorrente das intervenções físicas que seriam realizadas no ambiente costeiro local para viabilizar o empreendimento. Por exemplo, na página 68 do RIMA da UCN/OSX está indicado que um dos impactos ambientais previstos seria a "alteração da hidrodinâmica marinha e dos processos de erosão e sedimentação praial”. Ainda no RIMA da UCN/OSX, página 71, é apontado que essas mudanças teriam caráter irreversível. Já na página 80 está salientado que as modelagens apontaram no sentido de que haveria um processo discrepante de "engordamento" próximo ao quebra-mar (molhe) sul e de tendência à erosão no trecho subsequente ao engordado. Em função disso, o RIMA da UCN/OSX considera que o grau de relevância do impacto seria muito alto. Entretanto, já é possível perceber as alterações na linha de costa em um pequeno intervalo de tempo em função da construção de algumas obras costeiras do tipo quebra-mar, guia corrente e espigão (molhe). Tais alterações podem ser identificadas a partir das imagens de satélite disponíveis no Google Earth (2003 a 2014), onde se pode verificar um acúmulo de sedimentos na parte sul da área portuária.

Esse tipo de alteração na morfologia da linha de costa já foi identificado em outros locais onde existem obras portuárias. Magine et al. (2011) em um estudo sobre a zona costeira sob influência do porto do Pecém, no Ceará, puderam avaliar tais mudanças no período entre 2005 e 2009 nos perfis de praia, em que se verificou progradação da linha de costa, chegando até centenas de metros em alguns perfis. Tais mudanças ocorreram em função de um aporte sedimentar que foi interpretado como resultante das edificações portuárias no que se refere à sedimentação costeira. Martinez (2009) em sua dissertação de 
mestrado também identificou alterações desse tipo na zona costeira sob influência do porto do Tubarão, em Vitória, no Espírito Santo, onde mostra que as obras portuárias influenciam na direção média do fluxo de energia nas praias adjacentes. $\mathrm{O}$ autor também mostra que, em longo prazo, a tendência da praia de Camburi é sofrer uma rotação acentuando os processos erosivos na porção ocidental.

\section{Objetivos}

O objetivo geral deste trabalho é identificar as alterações ocorridas na morfologia da linha de costa do litoral que abrange a área de influência direta do Porto do Açu a partir da construção das obras costeiras relacionadas ao porto. O objetivo específico é demonstrar a dinâmica da linha de costa antes e após a instalação das obras portuárias, além de mensurar os valores das áreas alteradas, aplicando o uso de ferramentas de geoprocessamento e verificando as alterações horizontais na linha de costa. A hipótese é de que as obras de engenharia do porto alterarão a dinâmica litorânea e a posição da linha de costa em sua área de entorno num curto período de tempo.

\section{Justificativa}

A principal justificativa para a realização deste trabalho são as crescentes intervenções que vem sendo feitas na área de estudo, onde já é possível identificar problemas de erosão costeira (ex. Praia do Açu) e alterações na posição da linha de costa, além da demanda de conhecimento sobre esta área em função do contexto ser relativamente recente. Vale ressaltar que estes acontecimentos colocam em risco não só a integridade dos sistemas naturais, como também colocam em risco as comunidades que vivem e possuem suas instalações no litoral, o que instiga ainda mais o desenvolvimento deste trabalho.

\section{4. Área de Estudo}

A área de estudo está localizada na bacia de Campos, especificamente no litoral norte fluminense, município de São João da Barra, distrito do Açu (Figura 01), e está situada na extremidade meridional da costa leste brasileira, na costa norte do estado do Rio de Janeiro e sul do Espírito Santo. Delimita-se ao sul pelo Alto de Cabo Frio que separa da Bacia de Santos e ao norte pelo Alto de Vitória que separa da Bacia do Espírito Santo (RANGEL et al., 1994). A área de estudo está integrada na porção superior da referida bacia, na costa do litoral norte do estado do Rio de Janeiro, especificamente no distrito do Açu, localizado

ao sul do município de São João da Barra. É a principal bacia sedimentar já explorada na costa brasileira e possui uma área de aproximadamente 100 mil quilômetros quadrados, segundo a Petrobrás. 

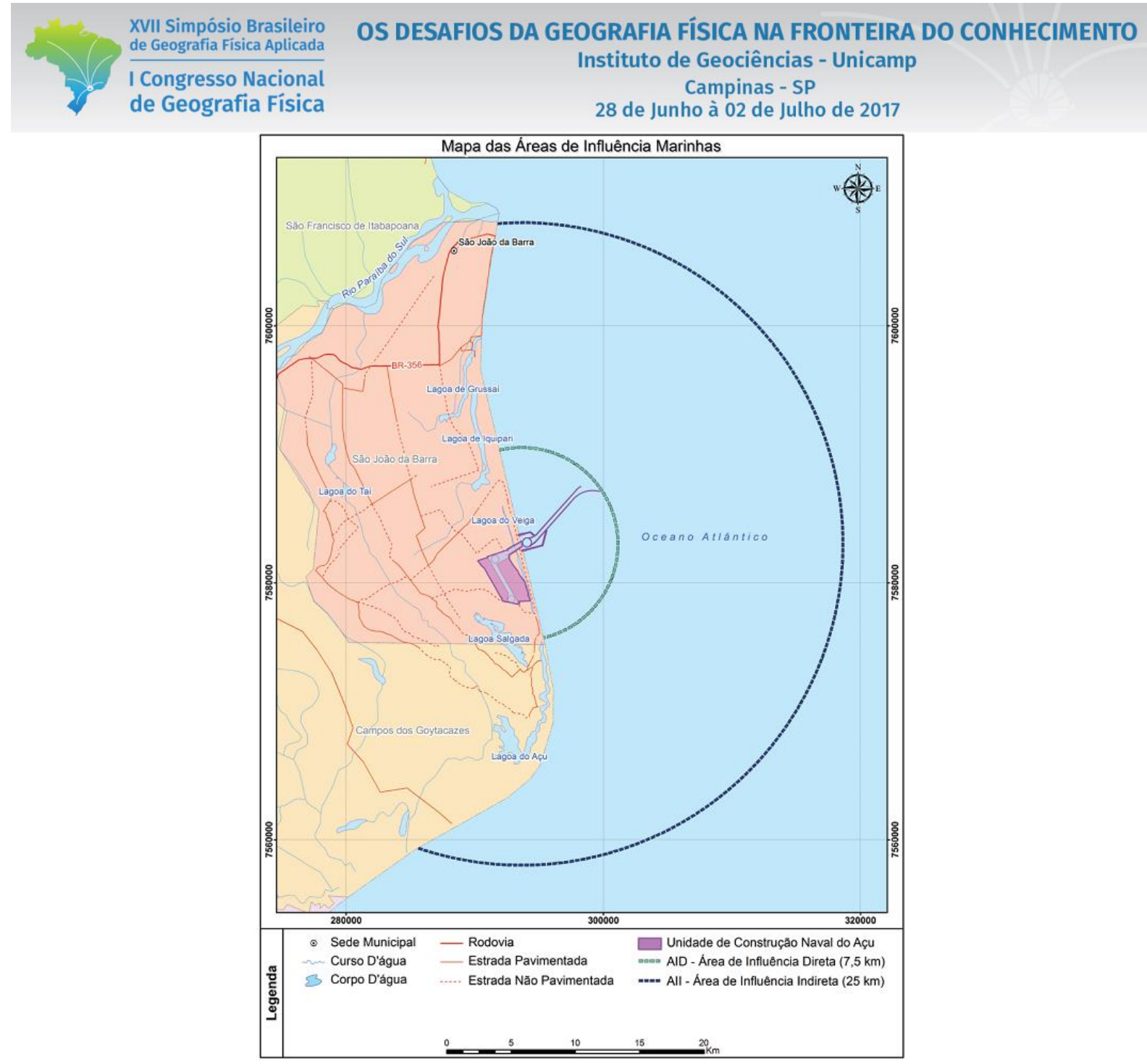

Figura 1 - Áreas de Influência Direta (AID) e indireta (AII) na Região Costeira, adjacente ao Porto do Açu. Fonte: RIMA Porto do Açu.

A planície costeira do rio Paraíba do Sul está inserida numa área caracterizada como de clima tropical úmido, com temperatura média de $22^{\circ} \mathrm{C}$. Apresenta uma estação chuvosa no verão e uma estação seca no inverno, indicando uma média anual de $1.300 \mathrm{~mm}$ (Costa, 1994 apud Bastos, 1997). Segundo Bernardes (1957), o mês de dezembro é tido como o mês com maior índice pluviométrico, com cerca de 150mm. Os ventos dominantes provêm do quadrante Nordeste (NE), associado à influência da Alta Pressão do Atlântico Sul, com velocidade em torno de 5-10 nós em média. Associados a passagem de frentes frias, os ventos Sul (S), Sudeste (SE) e em menor expressividade os de Sudoeste (SW) atingem a região principalmente no outono e no inverno (Pinho, 2003 apud Guimarães, 2005). Quanto à altura das ondas (Ho), observa-se uma altura média compreendida entre 1,6 e 2,0m. Observou-se ainda que as ondas com alturas superiores a 3,0 m são mais frequentemente oriundas dos quadrantes Sul (S) e Sudoeste (SW). 
Embora ocorra uma frequência bastante superior das ondas de Nordeste (NE) e Leste (E), quando comparada à distribuição de energia das ondas por direção de incidência e por mês, observa-se que as ondas de Su-Sudeste (SSE), Sul (S) e Su-Sudoeste (SSW) embora pouco frequentes, são as que concentram maior energia (Muehe \& Correa, 1989). Segundo informações da DHN para a Ponta de Imbetiba em Macaé, a amplitude de maré alcança 1,3 m em sizígia, caracterizando o regime de micro maré.

A atual planície costeira faz parte do complexo deltaico do rio Paraíba do Sul. Segundo Dias (1981), este complexo pode ser entendido como um conjunto de ambientes sedimentares relacionados, principalmente, a diversas fases de evolução do delta do rio Paraíba do Sul. Os processos evolutivos que desencadearam as principais transformações morfológicas no delta foram apresentados entre outros trabalhos por Dias \& Gorini (1980); Dominguez et al. (1981); Martin et al. (1984); Silva (1987); Bastos (1997). Apesar de algumas considerações discordantes em relação à evolução da área, em todos os trabalhos é consenso que o atual sistema de cristas de praia associadas à desembocadura do rio Paraíba do Sul foi formado numa situação regressiva do nível relativo do nível do mar, criando condições para um ambiente progradante da linha de costa nos aproximados últimos 5.000 anos.

As alterações na circulação hidrodinâmica marinha e dos processos de erosão e sedimentação na faixa costeira, sobretudo dentro da Área de Influência Direta (AID), são induzidas pelas atividades de dragagem do canal de acesso/atracação e da construção dos guiascorrente.

Cassar e Neves (1993) elaboraram um estudo sobre o residual de transporte litorâneo para as áreas costeiras na Bacia de Campos, e o principal resultado deste trabalho mostra um residual de transporte litorâneo de sedimentos direcionado para o norte na área de Barra do Açu na ordem de $500 \mathrm{~m}^{3} / \mathrm{dia}$. Na figura 02 é possível visualizar o transporte de sedimentos ao longo da costa do litoral Norte Fluminense. 


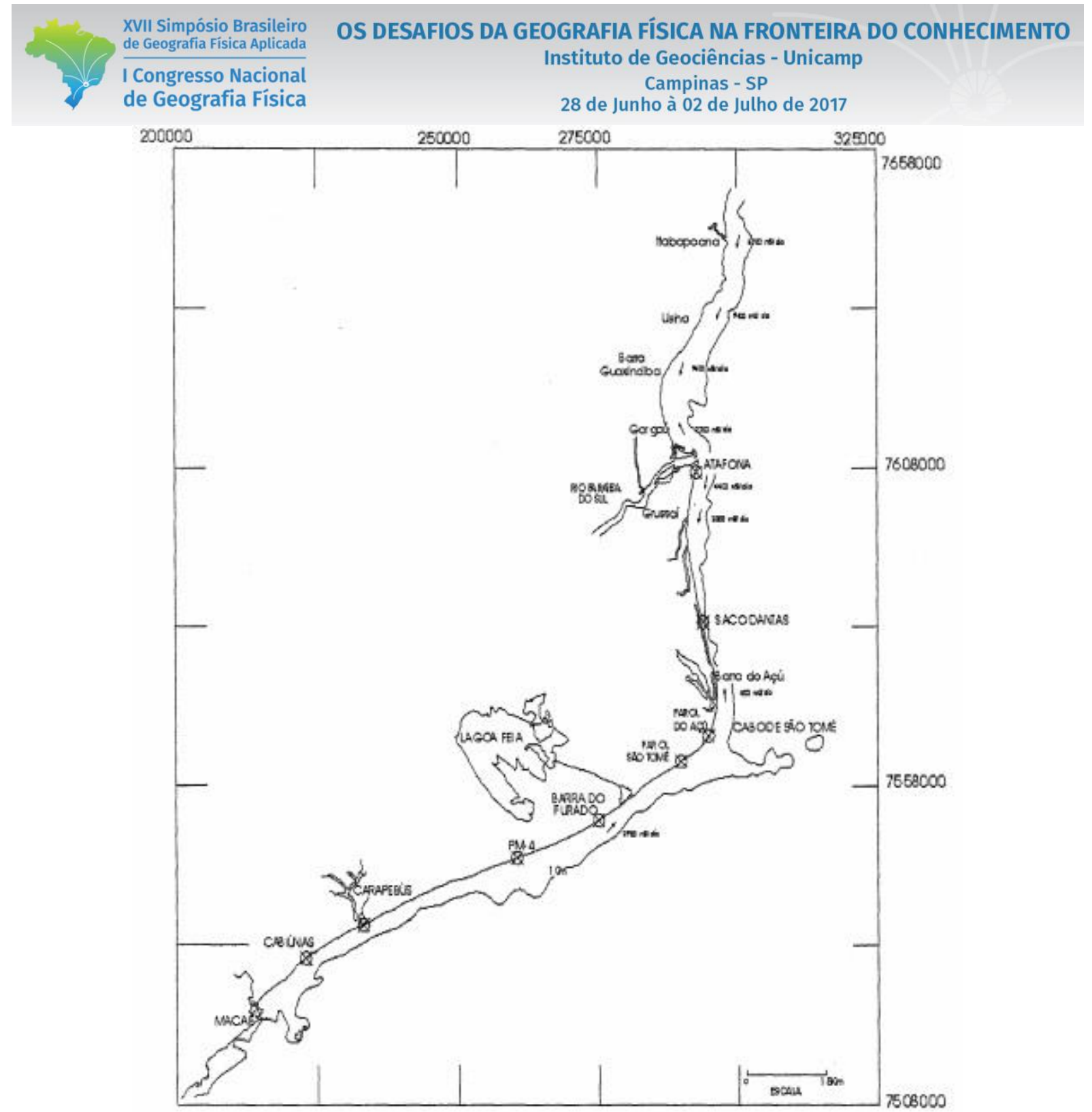

Figura 02 - Mapa indicando o sentido do transporte litorâneo ao longo do litoral norte fluminense por Cassar \& Neves (1993), e a localização das estações de perfilagem ao longo do litoral. (Projeção UTM, Meridiano Central-39).

Bastos e Silva (2000) frisam que o perfil de praia na localidade do Açu tem uma largura média de 100m, com um pós-praia plano com declive suave, marcado por uma crista de berma elevada seguida por uma face de praia íngreme $\left(8^{\circ}\right)$ e composta por areia grossa $(0,670 \mathrm{~mm})$. Normalmente, os perfis erosivos que se desenvolvem durante os períodos de tempestade, são caracterizados por um recuo da face da praia, que mantém seu alto gradiente, seguindo uma crista de berma. A principal característica do perfil de Farol do Açu é seu alto índice de mobilidade, sem que apresente tendências erosivas (naturais) notáveis como em 
Atafona. Vale ressaltar que a referida área está localizada geograficamente no Cabo de São Tomé onde o litoral ao norte com direção NNW-SSE sofre uma inflexão para SW-NE.

\section{Revisão Conceitual}

Uma básica definição para a linha de costa é a "linha que representa as bordas de um corpo d'água" (Dolan et al., 1978). Entretanto, as variações à que estão sujeitos esses ambientes e suas interfaces fazem com que essa linha seja extremamente dinâmica, apresentando constantes mudanças de posicionamento, sendo a definição de sua localização um pouco mais complexa.

A linha de costa brasileira foi delimitada a partir do Decreto-Lei ${ }^{\circ} 9.760$ de 05 de setembro de 1946 (Diário Oficial da União, 1946), com base na linha média de preamares de 1831. Esta lei instituiu a cobrança de impostos sobre uma faixa continental de 33m medidos a partir da linha média de preamares, faixa esta denominada de terrenos de marinha. Em fevereiro de 1998, foi promulgada outra Lei federal sob n 9.636 (Serviço Público da União, 2005), a qual estabeleceu a obrigatoriedade de compra dessas terras, para os proprietários que não comprovassem ter a sua posse a mais de 01 ano. Esta lei vem sendo constantemente protestada, por conta das inconsistências causadas por este indicador na definição da linha de costa. A posição ocupada pela linha de costa à época do decreto que instituiu seu indicador (linha média de preamares) tem sido alvo de pesquisas, como por exemplo, o estudo de Lima (2002) sobre "Localização geodésica da linha da preamar média de 1831 - LPM/1831", em que aborda o problema da demarcação dos terrenos de marinha e seus acrescidos, desenvolvendo uma metodologia e estabelecimento de um modelo científico que possibilita a localização geodésica da "Linha da Preamar Média de 1831 - LPM/1831" a partir da análise harmônica dos dados de marés de longo período, de modo que atenda a exatidão e a precisão das medidas compatíveis com as necessidades do levantamento cadastral destas parcelas imobiliárias inseridas entre os bens da União. Contudo, em virtude da dinâmica constante da linha de costa, a posição geográfica da linha média de preamares em 1831, em muitos lugares, já não corresponde mais com a realidade no que se refere à confrontação do mar com o continente. A posição da linha de costa é resultado de interações morfodinâmicas, controlada principalmente pelas características das ondulações geradas pelos sistemas meteorológicos e pelo balanço hídrico e sedimentar resultante entre o aporte continental e marinho. Somam-se a isso, as variações do nível do mar (Villwock \& Tomazelli, 1995).

Dentre os principais indicadores na análise da mudança da linha de costa, Smith e Zarillo (1990), Anders e Byrnes (1991) e Zhang et al. (2002), discutem a aplicação da linha de maré alta, onde segundo eles, tornase facilmente identificada devido a uma mudança de tom do sedimento que ocorre no local onde a água atinge seu ponto máximo. Hoek et al. (2001), entretanto, discordam da utilização desse indicador pois 
segundo eles, essa marca pode não ser nítida, e em alguns casos sequer aparecer como uma zona de transição ou simplesmente não aparecer na fotografia aérea. Fischer (2005) considera a linha da água como a feição menos confiável, já que é suscetível às variações de curto período; sendo, porém, considerada como bom indicador em praias arenosas de baixa declividade e areia fina por Absalonsen e Toldo Jr. (2006).

Norton (1997) e Marone (2007) sugerem que um dos melhores indicadores da linha de costa é a vegetação costeira, pois é pouco mutável em períodos curtos, eliminando a dificuldade de definição da hora da maré e sua extensão horizontal.

Partindo da ideia de Kraus \& Rosati (1997), uma das definições padrão em regra utilizadas para definir a linha de costa é a fronteira seco/molhado, no qual é fortemente dependente da própria praia, nível do mar, ondulação, regime de vento, etc. Neste trabalho será utilizada esta definição como base para definir a linha de costa na área de estudo, tendo como justificativa o fato de ser facilmente identificada por diferentes olhares, mais ou menos técnicos, além de atender as necessidades para os possíveis resultados deste trabalho.

Já as obras de abrigo portuário têm como funções reduzir os efeitos das correntes marítimas que atingiriam os navios atracados, além de conter o avanço da erosão na área e desassorear o canal, melhorando a navegabilidade das embarcações. Dentre as diversas obras portuárias existentes, no Porto do Açu é possível identificar, inicialmente, a existência de três: Quebra-mar, Guia-corrente e Espigão, que geralmente são obras comuns em portos. Caracterizando cada uma, de acordo com Alfredini \& Arasaki, 2009, temos o seguinte:

Quebra-mares: São elementos concebidos para travar a ação das ondas numa determinada área. São usados para proteger a costa, sendo posicionados de forma paralela à mesma, possuindo as duas extremidades dentro do mar. Esta proteção acontece devido às características destas estruturas, que dissipam e refletem a energia das ondas que as atingem. Desta forma, os quebra-mares são utilizados nos portos com o objetivo de facilitar a amarração de barcos, as operações de movimentação de cargas e a manutenção de navios, além de assegurarem a proteção das instalações portuárias propriamente ditas.

Espigões: São estruturas transversais que se estendem do pós-praia, suficiente enraizadas para não serem contornadas pelo espraiamento das ondas, após a linha de arrebentação mais externa, agindo diretamente sobre o transporte de sedimentos litorâneo na faixa em que ele é mais significativo e podem ser usados em conjunto ou isoladamente. Tem como funções interceptação de parte, ou totalidade, do transporte de sedimentos litorâneo, por meio de deposições (assoreamento); estabilização de praia sujeita a variações 


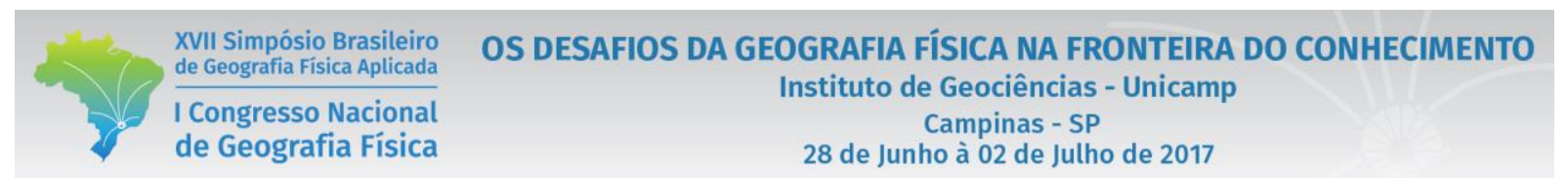

periódicas; alargamento de praia para fins balneários, ou de reurbanização; evitar assoreamento a sotamar (contenção de restingas ou flechas, por exemplo); complemento de fixação para a alimentação artificial.

Molhes (ou Guia Corrente): São estruturas longas e estreitas concebidas com o intuito de estabilizar canais de navegação, criar locais adequados de atracação que facilitem as manobras das embarcações, constituir zonas de abrigo contra ondas de tempestades e, ainda, proporcionar abrigo contra as correntes marítimas desfavoráveis na zona onde estão implantadas. O molhe possui uma extremidade em terra e a outra em mar.

\section{Materiais e Métodos}

A metodologia utilizada neste trabalho é a pesquisa bibliográfica e utilização de imagens de satélite para digitalização da fronteira seco/molhado (exemplo na figura 3) no período antes do início das obras do porto até às condições atuais, além do uso de softwares como o QuantumGis e ArcGis para obter resultados mais detalhados e de fácil leitura.
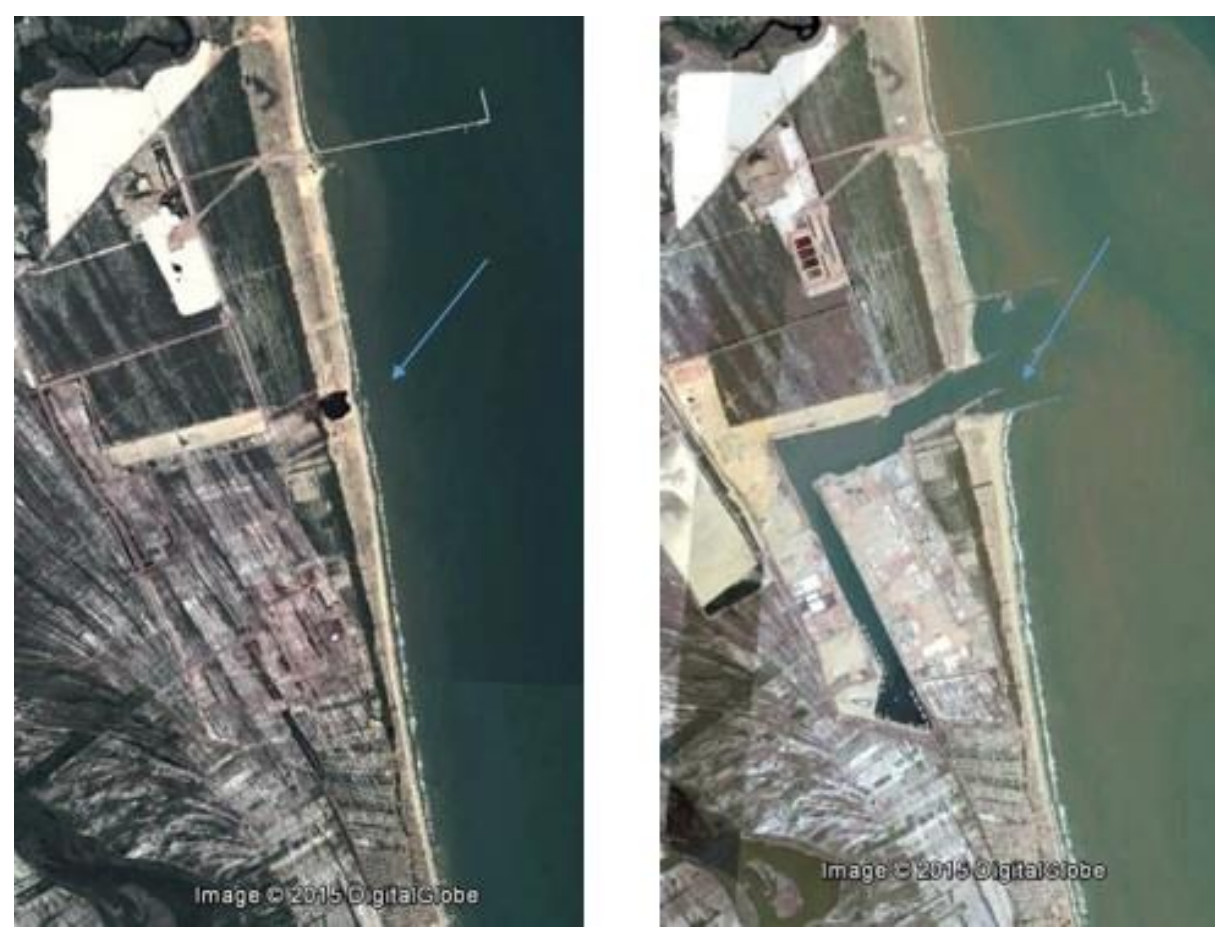

Figura 03 - Comparação entre a linha de costa da área de estudo em 2010 (esquerda) e em 2015. A seta azul indica o local de abertura do canal de navegação, área onde as alterações foram mais acentuadas. Imagens de satélite disponíveis no Google Earth Pro.

As imagens foram obtidas através do Google Earth Pro, onde, para a área de estudo trabalhada, estão disponíveis arquivos dos anos de 2003, 2010, 2011, 2013, 2014, e 2015. Vale ressaltar que as obras do 
porto se iniciaram em 2009, ou seja, partindo do que foi disponibilizado pelo Google Earth Pro, é possível visualizar o litoral antes e durante a construção das obras.

Através das imagens disponíveis no Google Earth Pro, foi feita a digitalização da linha de costa em arquivos vetoriais do tipo shape através do software QuantumGis, que posteriormente permitiu a sobreposição e diferenciação das linhas dos respectivos anos da linha de costa através de cores no ArcGis, ou seja, cada cor representa a linha de costa referente a um determinado ano. Os critérios utilizados para o limite da digitalização foi de $3,5 \mathrm{~km}$ ao norte do canal do porto, e $7 \mathrm{~km}$ ao sul (até a comunidade em Barra do Açú) com a justificativa de que acima de 3,5km ao norte já não existem mais alterações significantes, diferente do que ocorre ao sul do terminal 2 (molhe sul), onde as alterações são mais nítidas em uma faixa de até $7 \mathrm{~km}$. Em relação à escala de visualização da linha de costa para a delimitação da fronteira seco/molhado, foi utilizada a elevação de $1 \mathrm{~km}$ acima do nível do mar.

\section{Resultados}

Os resultados deste trabalho estão baseados na posição da linha de costa em seis diferentes anos, partindo do que está disponível no Google Earth Pro e fazendo a sobreposição das linhas que foram demarcadas na linha de costa das imagens anteriores com a imagem atual do referido litoral da área de estudo. A linha vermelha representa a linha de costa daquele litoral na referida data que está na parte superior de cada imagem, tendo como fundo a imagem do momento atual.

O dimensionamento perpendicular à linha de costa promove acúmulo dos sedimentos arenosos ao Sul do guia-corrente, sedimentos estes que estariam sendo transportados para o Norte. Além disso, os sedimentos que viriam transportados do Norte para o Sul, também tendem a ficar retidos junto às outras estruturas posicionadas para a proteção do porto (quebramar/molhe norte).

Em relação à progradação (avanço da linha de costa) e retrogradação (recuo da linha de costa) da área de estudo, foi visto que ao sul do guia-corrente houveram os maiores avanços e acumulo sedimentar devido ao contato direto dos sedimentos com a referida obra portuária. Na medida em que se afasta do guiacorrente em direção ao sul, esse acumulo vai diminuindo, sendo possível observar outros efeitos progradandes e retrogradantes de pequena intensidade (dimensão espacial) ao longo da costa até a comunidade do Açu, limite da área de estudo.

Para mensurar a alteração em área ao longo da área de estudo, os resultados extraídos a partir das rotinas de geoprocessamento mostraram que no período de 2003 a 2010, durante os 7 anos houve um aumento acumulado de 4,783 hectares, e as faixas de retrogradação, somadas resultam em 1,035 hectares. Já no 
período entre 2010 e 2015, momento em que se iniciaram as obras portuárias, foi possível visualizar uma progradação de 7,792 hectares e retrogradação de 1,325, ainda que o intervalo de tempo seja menor em relação ao período anterior. A tabela 1 mostra os respectivos períodos e valores em área.

\begin{tabular}{|c|c|c|}
\hline PERIODO / EFEITO NA LINHA DE COSTA & Progradação (ha) & Retrogradção (ha) \\
\hline $\mathbf{2 0 0 3}$ a $\mathbf{2 0 1 0}$ & 4,783 & 1,035 \\
\hline $\mathbf{2 0 1 0}$ a 2015 & 7,792 & 1,325 \\
\hline
\end{tabular}

Tabela I - Quantificação em área das alterações na linha de costa entre 2003 e 2015, em dois intervalos, baseada em meus resultados.

Para melhor visualização dos resultados, é possível fazer uma média anual da referida variação, indicando taxas médias para o efeito progradante quanto retrogradante. No primeiro espaço de tempo, houve uma média de progradação anual de 0,683 hectares, enquanto no período de 2010 a 2015 houve um aumento na média anual para 1,558 hectares. Já em relação a retrogradação, uma média anual, tem como resultado um recuo de 0,207 hectares ao ano entre 2003 e 2010, e no segundo período um recuo anual de 0,265 hectares. Partindo destes resultados, é possível perceber que no segundo intervalo de tempo, que possui 5 anos, aconteceram mudanças mais significativas do que no primeiro intervalo de tempo analisado, que possui 7 anos. Isso se deve ao fato da construção do porto ter sido iniciada no final da década de 2000 , com as obras de abrigo portuário no litoral sendo consolidadas no período de 2009 e 2010, ou seja, a partir da interferência dessas estruturas físicas, as mudanças na costa se acentuaram significativamente. Na figura 03, em um intervalo de 5 anos, é possível identificar uma tendência de acumulo de sedimentos junto ao Molhe sul.

\section{Conclusões}

Finalmente, é possível concluir que os métodos utilizados neste trabalho foram suficientes para se chegar aos resultados que já eram esperados. A relação entre economia e meio ambiente deve ser mais relevante com transparência, principalmente quando se trata do ambiente costeiro, onde já ocorre uma dinâmica natural relativamente acentuada e exige um comprometimento ainda maior com o planejamento. No caso da área de estudo foi possível visualizar e quantificar o quanto as estruturas físicas portuárias que se adentram ao oceano alteraram a linha de costa, cujo processo de construção se iniciou a menos de 10 anos e as mudanças já são nítidas.

É necessário a realização de estudos sobre a área da praia do Açu e identificar as flutuações em área da referida praia, entretanto, a questão que aparece como altamente significativa é que não apenas o monitoramento deva ser feito e que seus resultados sejam devidamente publicados, mas que estes estudos 
sejam iniciados imediatamente para que ações possam ser tomadas de modo a evitar a persistência do processo a sua intensificação. É importante também que sejam feitos levantamentos sobre as perdas já ocorridas na infraestrutura urbana e também sobre unidades residenciais que estejam mais próximas da linha da costa.

O meio ambiente jamais deve ficar em detrimento das atividades econômicas, ele deve ser pensado em primeiro plano e as atividades devem se adaptar aos diferentes meios de forma que não agrida, pois na maioria das vezes as mudanças na natureza são de caráter cada vez mais irreversíveis, contribuindo para o desequilíbrio ambiental em prol do desenvolvimento econômico.

\section{REFERÊNCIAS}

ALFREDINI, Paolo; ARASAKI, Emilia. Obras e gestão de portos e costas: a técnica aliada ao enfoque logístico e ambiental. 2 ed. São Paulo: Blucher, 2009. 776 p.

ANDERS, F. J., and BYRNES, M.R., 1991. Accuray of Shoreline Change Rates as Determined From Maps and Aerial Photographs. Shore and Beach, 59(1): 17-26.

BASTOS, A. C. 1997. Análise Morfodinâmica e Caracterização de Processos Erosivos ao Longo do Litoral Norte Fluminense, Entre Atafona e Cabiúnas, RJ, Brasil. Dissertação de mestrado. Universidade Federal Fluminense, Departamento de Geologia. 135p.

BASTOS, A. C; SILVA, C.G. Caracterização Morfodinâmica do Litoral Norte Fluminense, Revista Brasileira de Oceanografia. Niterói, 48(1): 41-60, 2000.

BERNARDES, L. M. C. Planície litorânea e zona canavieira do Estado do Rio de Janeiro. Conselho Nacional de Geografia, Rio de Janeiro. 1957.

CAL, Consultoria Ambiental Ltda. Porto do Açu - RJ: RIMA - Relatório de Impacto ao Meio Ambiente. Volume Único. Agosto/2006.

CANCIAN, T. B. Evolução Recente e Predição da Linha de Costa da Praia de Camburi, Vitória-E.S. Vitória, 2009.

CASSAR, C. M.; NEVES, C. F. 1993. Aplicação das Rosas de Transporte Litorâneo à Costa Norte Fluminense. RBE, 11:81-103.

CHRISTOFOLETTI, A. Geomorfologia. 2 ed. São Paulo: Edgar Blücher, 1979.

DIAS, G.T.M. 1981. O Complexo Deltáico do Rio Paraíba do Sul. In: Simpósio do Quaternário no Brasil. Publicação Especial. No.2 p.58-88.

DIAS, G.T.M., GORINI, M.A.A. 1980. Baixada Campista: Estudo Morfológico dos Ambientes Litorâneos. Anais do XXXI Congresso Brasileiro de Geologia. Camboriú. Vol. 1: 588-602.

DOLAN R.; HAYDEN, B.; HEYWOOD, J. 1978. A New Photogrammetric Method for Determining Shoreline Erosion Coastal Engineering, 2: 21-39. Elsevier Scientific Publishing Company, Holanda.

DOMINGUEZ, J.M.L.. BITTENCOURT, A.C.S.P. e MARTIN, L. - 1981 - Esquema evolutivo da sedimentação quaternária nas feições deltaicas dos rios São Francisco (SE AL), Jequitinhonha (BA), Doce (ES) e Paraíba do Sul (RJ). Rev. Bras. Ceoc. 11(4):227-23.

KRAUS, N. C; J.D. ROSATI. Interpretation of shoreline - Position Data For Coastal Engineering Analysis. Coastal Engineering Technical Note, CETN II-39, U.S. Army, Engineer Research and Development Centre, Vicksburg, M.S. 1997. 
MAGINE, Christiano. A Influência Da Estrutura Portuária Na Dinâmica Costeira na Vila do Pecém, Ceará, Brasil. Revista de Geologia, Vol. 24, nº 2, 136 - 149, 2011

MARQUEZ, Andre L. Estudo de agitação, correntes induzidas por ondas e balanço sedimentar da região do porto do tubarão e praia de Camburi, Vitória / ES. USP, instituto oceanográfico. São Paulo, 2009.

MARTIN, L.; SUGUIO, K.; DOMINGUEZ, J.; FLEXOR, J.M.; AZEVEDO, A. 1984. Evolução da Planície Costeira do Rio Paraíba do Sul (RJ) Durante o Quaternário: Influência das Flutuações do Nível do Mar. Anais do XXXIII Congresso Brasileiro de Geologia. Rio de Janeiro.

MUEHE, D. Geomorfologia Costeira. In: GUERRA, A.J.T. \& CUNHA, S.B. (eds), Geomorfologia: Uma atualização de bases e conceitos. Rio de Janeiro, Bertrand Brasil, 1994.

MUEHE, D. O Litoral Brasileiro e sua Compartimentação. In: CUNHA, S. B. e GUERRA, A. J. T.(org). Geomorfologia do Brasil. Bertrand Brasil: Rio de Janeiro, 1998.

MUEHE, D.; CORRÊA, C.H.T. (1989) - The Coastline Between Rio de Janeiro and Cabo Frio. In: Claudio Neves (ed.), Coastlines of Brazil, pp.110-123, American Society of Civil Engineers (ASCE), New York, NY, U.S.A. ISBN: 978-0872627079.

NORDSTROM, Karl F. Recuperação de praias e dunas. São Paulo: Oficina de textos, 2010. 263 p.

PETROBRAS. Bacia de campos. Disponível em: <http://www.petrobras.com.br/pt/nossasatividades/principaisoperacoes/bacias/bacia-de-campos.htm>. Acesso em: 05 nov. 2014.

RANGEL, H.D.; MARTINS, F.A.L.; ESTEVES, F.R. \& FEIJÓ, F.J. - 1994. Bacia de Campos. In: Boletim de Geociências da Petrobras nº1, vol.8. PETROBRAS. Rio de Janeiro, Brasil.

ROCHA, T. Morfodinâmica Costeira e Gestão de Orla Marítima em Costa Sob Influência Fluvial: Borda meridional do atual delta do Rio Paraíba do Sul (RJ). 2009. 141 f. Dissertação - Universidade Federal Fluminense. Niterói, 2009.

SILVA, C. G. 1987. Estudo da Evolução Geológica e Geomorfológica da Região da Lagoa Feia, RJ. Dissertação de mestrado. Universidade Federal do Rio de Janeiro, Departamento de Geologia.116p.

SMITH, G. L., and ZARILlO, G. A., 1990. Calculating Long-term Shoreline Recession Rates Using Aerial Photograpgic and Beach Profiling Techniques. In: Journal of Coastal Research, v. 6, no. 1, p. 111-120.

SOUZA, M. H. S. 1988. Clima de ondas do norte do estado do Rio de Janeiro. Dissertação de Mestrado. PósGraduação em Engenharia Oceânica, Universidade Federal do Rio de Janeiro/ COPPE, 181p.

ZHANG, K.; HUANG, W.; DOUGLAS, B.C., and LEATHERMAN, S.P. Shoreline Position Variability and Long-term Trend Analysis. Shore and Beach, n.70, v.2, p.31-35, 2002. 